\title{
Link between vertical and horizontal movement patterns of cod in the North Sea
}

\author{
Victoria J. Hobson ${ }^{1,2, *}$, David Righton ${ }^{2}$, Julian D. Metcalfe ${ }^{2}$, Graeme C. Hays ${ }^{1}$ \\ ${ }^{1}$ Institute of Environmental Sustainability, Swansea University, Singleton Park, Swansea SA2 8PP, UK \\ ${ }^{2}$ Centre for Environment, Fisheries and Aquaculture Science, Lowestoft Laboratory, Pakefield Road, Lowestoft, \\ Suffolk NR33 0HT, UK
}

\begin{abstract}
We used a geolocation method based on tidal amplitude and water depth to assess the horizontal movements of $14 \mathrm{cod}$ Gadus morhua equipped with time-depth recorders (TDR) in the North Sea and English Channel. Tracks ranged from 40 to $468 \mathrm{~d}$ and showed horizontal movements of up to $455 \mathrm{~km}$ and periods of continuous localised residence of up to $360 \mathrm{~d}$. Cod spent time both in midwater ( $43 \%$ of total time) and near the seabed (57\% of total time). A variety of common vertical movement patterns were seen within periods of both residence and directed horizontal movement. Hence particular patterns of vertical movement could not unequivocally define periods of migration or localised residence. After long horizontal movements, cod tended to adopt resident behaviour for several months and then return to broadly the same location where they were tagged, indicating a geospatial instinct. The results suggest that residence and homing behaviour are important features of Atlantic cod behaviour.
\end{abstract}

KEY WORDS: Groundfish · Horizontal movement - Geolocation · Vertical behaviour · Locational accuracy $\cdot$ Hidden Markov model

Resale or republication not permitted without written consent of the publisher

\section{INTRODUCTION}

Animal movements often play a central role in the animal's ecology and are important for applied management of exploited or endangered species, especially marine species (Stewart et al. 1989, Weimerskirch et al. 1993, Schofield et al. 2009). The evolution of a range of tracking technologies has allowed the movements of some species to be determined in great detail. For aquatic animals that surface (e.g. marine mammals, birds and reptiles), Argos transmitters that relay positional data through low-earth-orbit satellites can provide near-real-time information on location (e.g. Hays et al. 2006, Pinaud \& Weimerskirch 2007). For marine animals that never surface, such as most species of fish, long-term tracking has generally been achieved using light-based geolocation, i.e. by recording light levels with a tag attached to the animal and then using the time of sunrise and sunset to determine longitude and the length of the day to determine latitude. These data are stored in tag memory and then downloaded if the tag is retrieved or relayed via satellite pop-off tags (e.g. Sims et al. 2005).

Despite the wide use of light-based geolocation, some fish remain difficult to track, such as demersal species in turbid costal environments, where lightbased geolocation is highly inaccurate. Yet for many of these species, tracking data are desirable to improve the management of the species. Given this broad interest in tracking coastal species in turbid water, tidebased geolocation methods (and other geolocation methods based on environmental data) have been developed (Hunter et al. 2004a, Gröger et al. 2007, Neuenfeld et al 2007, Righton \& Mills 2008). The tidebased approach uses detailed models of tidal amplitudes and tide times over extended areas. By using a data-logger to measure the water depth for animals that are not moving vertically, such as flatfish resting on the seabed, the times of high water and tidal amplitudes can then be compared to spatial models to predict the location of the tagged individual. This approach has been widely used in the North Sea with benthic species 
such as plaice and rays (Hunter et al. 2003, 2006). However, the approach may also be used for demersal species that spend extended periods at the same depth, so that attached loggers can again record tide times and amplitudes.

One species of great commercial importance in shelf seas at high latitudes is the Atlantic cod. There is great concern over the decline in stock sizes for the cod Gadus morhua, particularly in the North Sea and the Grand Banks in the last 20 yr (Myers et al. 1997, Christensen et al. 2003, Horwood et al. 2006). While the understanding of cod movements is increasing (Turner et al. 2002, Robichaud \& Rose 2004, Neat et al. 2006, Svedäng et al. 2007), the development of a mechanistic understanding of these movements may allow the availability of cod fishing potential at different spatial and temporal scales (O'Brien et al. 2000). Similarly, information on cod depth utilisation (e.g. if it is associated with the seabed or in midwater) may have implications for how accessible cod are to different gear types (Walsh et al. 2004, Nichol \& Chilton 2006). Ultimately, the ability to track cod for extended periods might also help to define areas for closure to fishing, such as marine protected areas (MPAs), and help to provide management guidance (Aglen et al. 1999, Roberts et al. 2005, Hunter et al. 2006). More detailed information on horizontal and vertical movements also allows the evaluation of the behavioural strategies employed during migrations. Many longdistance marine migrants show behavioural traits that optimise the efficiency of travel or food acquisition during journeys. Green turtles migrating to breeding areas, for example, travel beneath the surface at depths that minimise surface drag (Hays et al. 2001a). Some fish, particularly flatfish such as plaice, make selective use of tidal currents to minimise the costs of directed travel (Harden Jones et al. 1979, Arnold et al. 1994). In other species, extended horizontal travel may also be linked to extended vertical movements as individuals search the water column for prey (Bonfil et al. 2005, Sims et al. 2005, Hays et al. 2006). However, for cod and many other demersal species, the linkage between vertical and horizontal movements is poorly defined (Arnold et al. 1994). Given this interest in both vertical and horizontal movements and the phenology of migration, combined with the commercial value of cod, here we set out to use a recently developed tide-based geolocation method (Pedersen et al. 2008) to assess the horizontal movement of Atlantic cod G. morhua. In the present study, we reconstructed the tracks of cod in the North Sea and English Channel over periods of many months and assessed how their horizontal movements were linked to their vertical movement behaviour, and how these varied over periods of up to 14 mo.

\section{MATERIALS AND METHODS}

As part of a northwest European project (COD YSSEY, www.codyssey.co.uk), a large number of cod in the North Sea were equipped with TDRs over the last $9 \mathrm{yr}$. We analysed the movements of 14 of the longest records from the southern North Sea and English Channel to gain insight into the links between horizontal and vertical movements. Tags were attached to cod either externally or internally, as described in Neat et al. (2006) and Righton et al. (2006). The tagged fish varied in size from 48 to $65 \mathrm{~cm}$ total length (mean $\pm \mathrm{SD}=56 \pm 5 \mathrm{~cm}, \mathrm{n}=14$ ). Tags were programmed to record pressure and temperature every 10 or $20 \mathrm{~min}$.

Reconstructing migration paths. Hydrostatic (tidal) data, derived from the sinusoidal pressure cycle recorded in the depth data when a fish is at rest on the seafloor, was used to enable the geographical reconstruction of a cod's movements (hereinafter termed geolocation). This method is referred to as the tidal location method (TLM, as described in Metcalfe \& Arnold 1997; Hunter et al. 2004b). We used a novel Fokker-Planck-based method that combines the TLM with a hidden Markov model to estimate, for each day at liberty, the non-parametric probability distribution of geographic position (for details see Pedersen et al. 2008).

Estimating location error. To estimate the location error of the geolocation method we first identified 13 periods of residence of $>2 \mathrm{wk}$ (see Fig. 1) where the fish showed strong affinity to the seabed and no movement upwards into the water column, i.e. a clear tidal sine wave was seen at all times in the depth data, with a stable mean depth. We then assumed that the fish remained in the same place during this period. For each period of residence we then calculated the SD for the latitude and longitude around the mean location.

Identifying periods of behaviour. Periods of residence were first identified by eye (see Fig. 2), defined as periods when the geolocation estimates showed that the fish was in the same area (deviating $<20 \mathrm{~km}$ from the central point of residence) for a period of time $>1 \mathrm{wk}$. A period of extended directed movement (EDM) was defined as when the fish made a distinct movement in the same direction for $>1 \mathrm{wk}$. Periods of behaviour that were $<1$ wk for both travel and residence were not included in this analysis and were classified as extended localised movement (ELM). The sum distance travelled from the start point to the end point of the period of behaviour and the speed of travel was then calculated using the great circle equation.

The speed of travel was determined separately for each period of behaviour, i.e. the sum total distance moved from the start position of that behaviour to the 
end position of that behaviour was divided by the number of days that the behaviour occurred. In this way we avoided compounding daily errors from the geolocation errors (Hays et al. 2001b).

The predominant vertical movement pattern for each day the fish was at liberty was determined using the vertical movement classifications defined in Hobson et al. (2007), who identified 4 principal classes: large descents towards the seabed away from the median depth, described as midwater (MW); continuous ascents into midwater or descents towards the seabed (continuous search, CS); close association with the seabed but with ascents into midwater (SW); and finally, seabed residence (SB). To examine whether cod in residence or in an EDM phase showed a particular vertical movement pattern in their behaviour we first calculated the proportion of time for each vertical movement pattern for each period of migration or residence.

To determine the probability of a fish beginning migration in a particular month, we determined the number of fish beginning migration in that month divided by the number of days that data were recorded in that month.

\section{RESULTS}

In total, the data set we collected for 14 fish totalled $3209 \mathrm{~d}($ mean $\pm \mathrm{SD}=229 \pm 146 \mathrm{~d})$.

\section{Periods of behaviour}

For the 13 occasions when the fish was classified in an extended period of residence ( $>2 \mathrm{wk})$, the mean error (Table 1) of the geolocation method (Fig. 1) was $8.6 \mathrm{~km}(\mathrm{SD}=4.3 \mathrm{~km})$. There was a small but significant difference between the mean longitudinal $(4.6 \mathrm{~km})$ and the mean latitudinal error $(5.9 \mathrm{~km})$ (paired $t$-test, $\left.t_{12}=3.0, \mathrm{p}<0.01\right)$.

For the 14 fish tracks analysed (area of attachment: southern North Sea $=9$, Jutland bank = 1, English Channel $=4$; Table 2), 18 periods of EDM and 24 periods of residence were identified. Overall for the 14 fish, the proportion of time spent in the 3 behaviours (EDM, ELM and resident) were 8, 25 and $67 \%$ respectively. The distance moved during an EDM phase ranged from 42 to $455 \mathrm{~km}$ (mean $\pm \mathrm{SD}=195 \pm 95 \mathrm{~km}$ ), with mean \pm SD speed of $17.6 \pm 11.4 \mathrm{~km} \mathrm{~d}^{-1}$. For example, Cod 6448 was tagged in the eastern English Channel (Fig. 1a) and travelled west for $9 \mathrm{~d}$, covering over $200 \mathrm{~km}$ at a mean speed of $25 \mathrm{~km} \mathrm{~d}^{-1}$. Maximum speed of travel occurred for 1 fish exhibiting selective tidal stream transport (STST). This fish (Cod 2255.2) was
Table 1. Number of geolocations obtained for each individual, the $\mathrm{SD}$ of the longitudinal and latitudinal location errors $\left(\mathrm{SD}_{X}\right.$ and $\mathrm{SD}_{y}$ respectively) and the deviation (mean $\pm \mathrm{SD}$ ) of locations from the mean position

\begin{tabular}{|lcrrc|}
\hline $\begin{array}{l}\text { Cod tag } \\
\text { ID }\end{array}$ & $\begin{array}{c}\text { No. of } \\
\text { locations }\end{array}$ & $\begin{array}{r}\mathrm{SD}_{x} \\
(\mathrm{~km})\end{array}$ & $\begin{array}{r}\mathrm{SD}_{y} \\
(\mathrm{~km})\end{array}$ & $\begin{array}{c}\text { Deviation } \\
(\mathrm{km})\end{array}$ \\
\hline 1079 & 56 & 7.3 & 8.3 & $12.6 \pm 7.0$ \\
1210 & 54 & 3.5 & 3.4 & $6.2 \pm 2.4$ \\
1429 & 80 & 13.0 & 20.5 & $24.8 \pm 15.9$ \\
1432 & 16 & 3.8 & 10.2 & $10.4 \pm 5.2$ \\
1432 & 40 & 4.5 & 3.2 & $6.8 \pm 4.2$ \\
1459 & 22 & 3.5 & 3.8 & $6.4 \pm 2.2$ \\
2026 & 17 & 3.6 & 4.1 & $6.6 \pm 2.4$ \\
2026 & 18 & 2.6 & 3.2 & $4.8 \pm 2.1$ \\
2026 & 30 & 3.1 & 3.3 & $5.4 \pm 3.4$ \\
2026 & 286 & 4.7 & 7.3 & $9.6 \pm 4.6$ \\
946 & 92 & 4.2 & 3.7 & $6.9 \pm 3.7$ \\
861 & 70 & 3.4 & 3.1 & $5.8 \pm 2.3$ \\
861 & 15 & 3.4 & 3.3 & $5.7 \pm 2.7$ \\
\hline
\end{tabular}

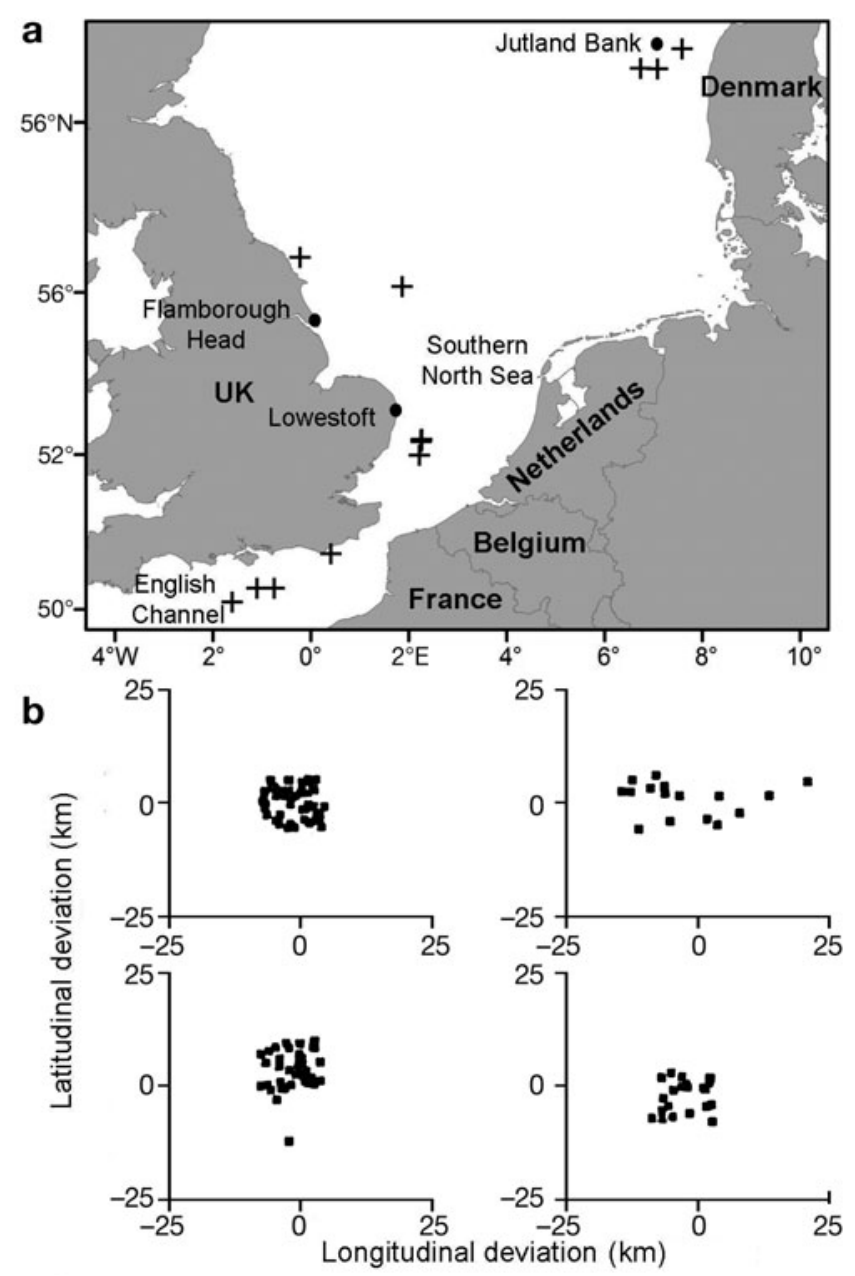

Fig. 1. (a) Regions where cod were tagged (Jutland Bank, southern North Sea and English Channel) and locations of the 'periods of residence' used to determine minimum error $(\mathbf{+})$. (b) Examples of periods of residence, showing the normalised spread of locations used to calculate the minimum error of geolocations 


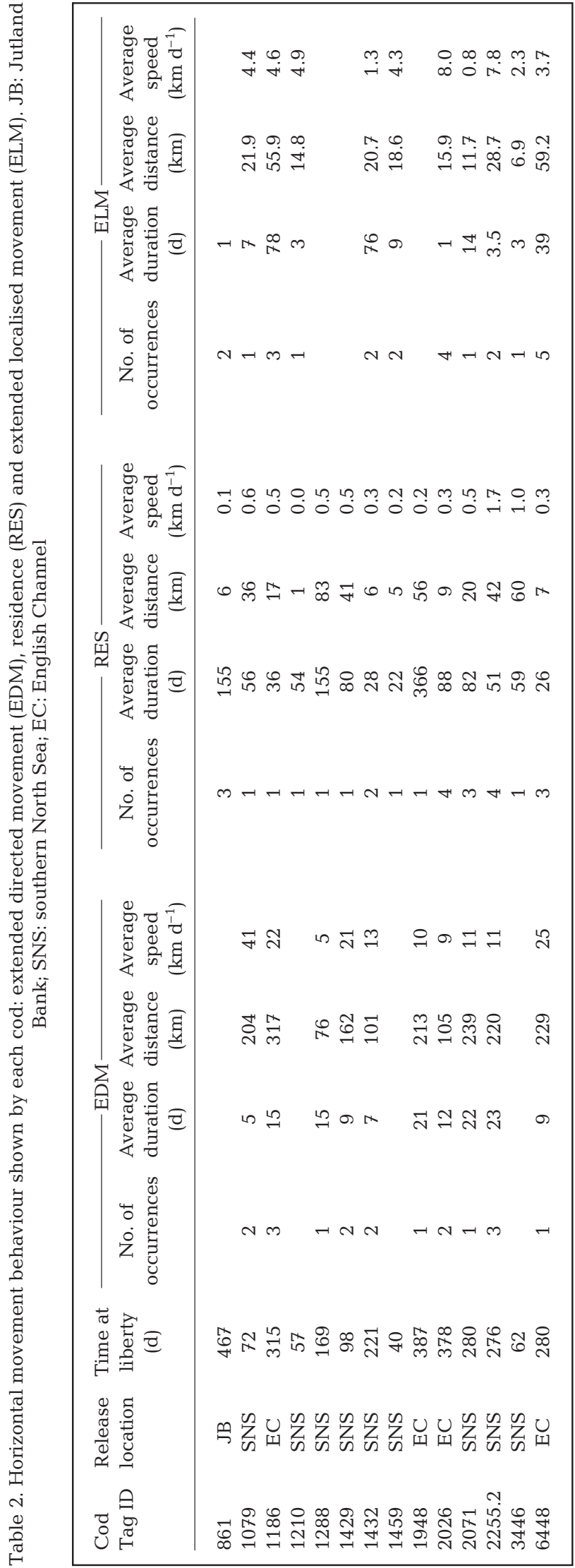

tagged near Lowestoft in the southern North Sea, and it travelled north up the English coast to Flamborough Head over $8 \mathrm{~d}$, travelling at a mean speed of $47 \mathrm{~km} \mathrm{~d}^{-1}$ (Fig. 2a). The fish repeatedly spent a full tidal cycle (approx. $12 \mathrm{~h}$ ) on the seabed, where a tidal signal could be seen, then rose into the water column for several hours, presumably taking advantage of favourable tidal currents. This was the only occasion of STST in this data set, i.e. of a total of $5880 \mathrm{~h}$ for fish spent undertaking EDM, only $408 \mathrm{~h}(7 \%)$ was spent in overt STST.

Speeds of travel during periods of residence were always $<5 \mathrm{~km} \mathrm{~d}^{-1}$ (Fig. 3). Periods of continuous localised residence ranged from 10 to $380 \mathrm{~d}$ (mean $\pm \mathrm{SD}=89.5 \pm$ 107.5 d). For example, Fish 861 tagged on the Jutland Bank (Fig. 1a) spent over a year in roughly the same vicinity, rarely moving off the seabed. Periods of ELM ranged from 1 to $213 \mathrm{~d}$ (mean $\pm \mathrm{SD}=45.7 \pm 81.9 \mathrm{~d}$ ). The total distance travelled during ELM phases varied from 7 to $82 \mathrm{~km}($ mean $\pm \mathrm{SD}=34 \pm 23 \mathrm{~km})$, with a mean $\pm \mathrm{SD}$ speed of $4.2 \pm 3.1 \mathrm{~km} \mathrm{~d}^{-1}$.

Four vertical movement types occurred (Fig. 4). During EDM, $26 \%$ of the time was spent in the water column in either MW or CS behaviour, and $74 \%$ was associated with the seabed (behaviour type SW or SB). During the periods of residence, less time was spent in midwater (17\%, vertical behaviour MW and CS) and $83 \%$ of time near the seabed (69\% was strongly associated with the seabed). All vertical movement behaviours were seen in both travelling (Fig. 2a,b) and residential periods (Fig. 2c,d). There were no significant differences between the amount of time spent in any of the behaviours for both the travelling and resident periods (ANOVA; midwater: $F_{1,40}=0.76, \mathrm{p}=0.38$; continuous searching: $F_{1,40}=0.95, \mathrm{p}=0.33$; seabed: $F_{1,40}=0.09$, $\mathrm{p}=0.76$; seabed with ascents: $F_{1,40}=2.39, \mathrm{p}=0.13$ ).

Some fish showed evidence of local repositioning (Fig. 5) where 3 periods of residence occurred between February and May in quick succession, but each in a slightly different locality. For example, Cod 6448, for which all 3 periods of residence were of a similar duration (mean $\pm \mathrm{SD}=26 \pm 3 \mathrm{~d}$ ), showed slow speeds (mean $=0.3 \mathrm{~km} \mathrm{~d}^{-1}$ ) and spent $95 \%$ of the time associated with the seabed.

\section{Timing of behaviour}

The onset of EDM occurred throughout the year (Fig. 6) depending on the individual fish, though a larger sample size would help to discern any migration patterns. Fish often start migrations in the winter months, such as Cod 2026; however, several other cod showed no signs of migration during winter, but started EDM in June (e.g. Cod 1429). 

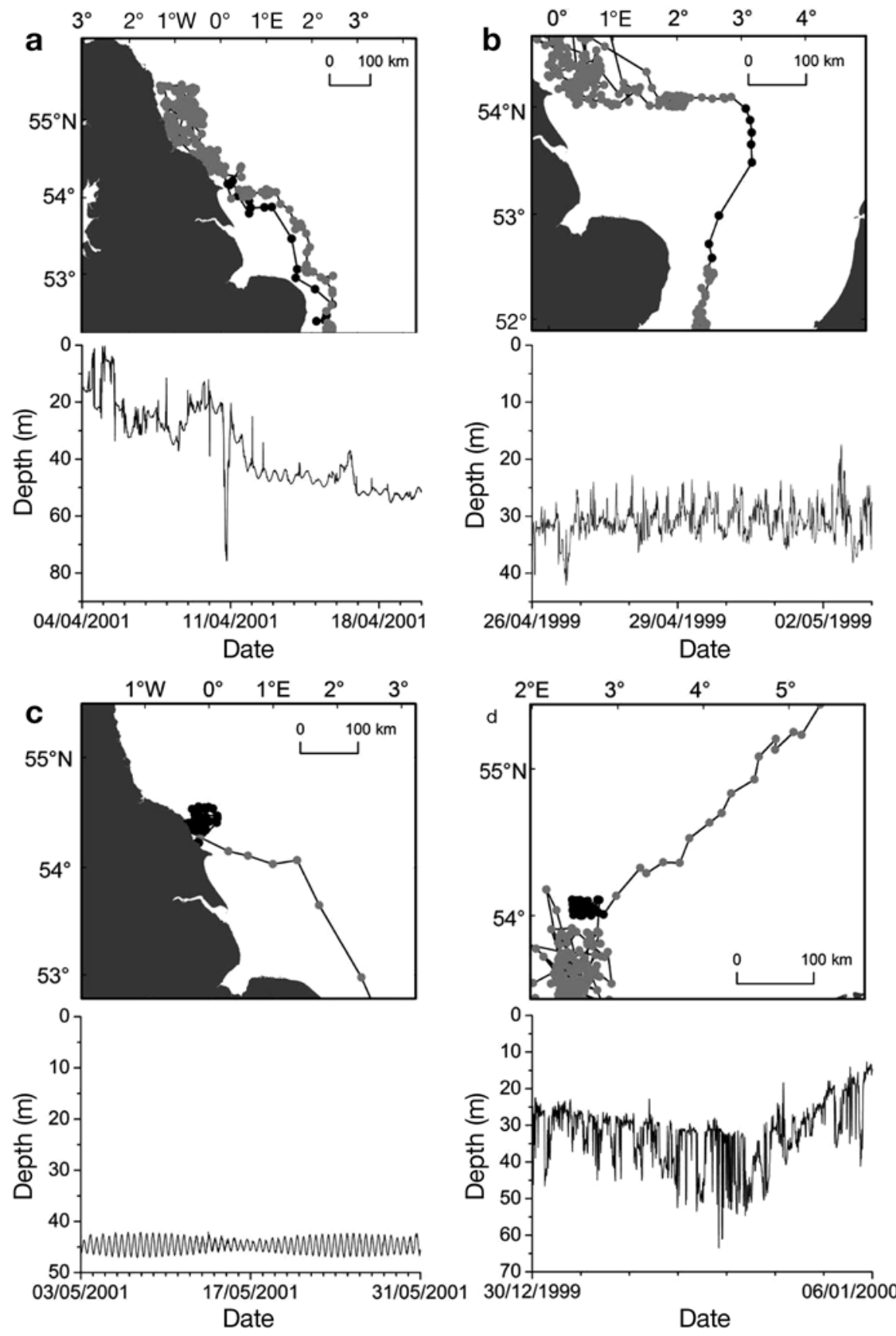

Fig. 2. Examples of track showing (a) directed horizontal movements associated with the seabed, (b) directed horizontal movements in midwater, (c) residence associated with the seabed and (d) residence in midwater. Periods of residence $(\bullet)$ and extended localised movement $(\bullet)$, with the corresponding depth trace illustrating vertical behaviour shown below each track panel. Note different time scales on depth traces

\section{DISCUSSION}

A key aspect of the present study was to use a new geolocation approach to estimate the position of cod. For any tracking technology it is important to assess location error as this impacts any subsequent move- ment analysis (Bradshaw et al. 2007, Patterson et al. 2008). There are various options to estimate location accuracy. First it is possible to leave tags in known locations and then to examine the data collected. This approach has been used, for example, with Argos transmitters (Hays et al. 1991, 2001b). However, tags in fixed locations might not perform in exactly the same way as tags attached to animals. So a second approach is to attach tags to animals that are kept in enclosures to ensure they are essentially in a fixed position (e.g. Vincent et al. 2002, Schaefer \& Fuller 2006). In the present study we made use of occasions when there was both (1) very little vertical movement by fish which implies that the fish were stationary and (2) geolocation estimates that showed no EDM. We then used repeated geolocation estimates from such periods to infer the accuracy of locations. This is likely to give a conservative estimate of location accuracy since in practice the fish may have been moving, to some extent, during these periods, so the scatter of locations we generated would be produced by a combination of geolocation errors and fish movement. The mean error estimated from our method was approximately $8 \mathrm{~km}$, which accords with estimates provided from data collected by stationary tags tested in the hidden Markov model geolocation method (Pedersen et al. 2008). To put this error into context, it is comparable to the worst Argos locations (Hays et al. $2001 \mathrm{~b}$ ) and is an order of magnitude better than light-based geolocation (Teo et al. 2004). This level of accuracy provided by the hidden Markov model geolocation method clearly means that migrations, sometimes extending several 100 s of $\mathrm{km}$, could be clearly identified. Of particular importance is the fact that the present results show that small data-storage tags clearly have the potential to allow the relatively fine-scale horizontal movements of small demersal fish to be determined in highly turbid coastal environments where traditional light-based geolocation would not work.

We have used the technique to demonstrate that some cod could perform long migrations (up to $454 \mathrm{~km}$ ). 

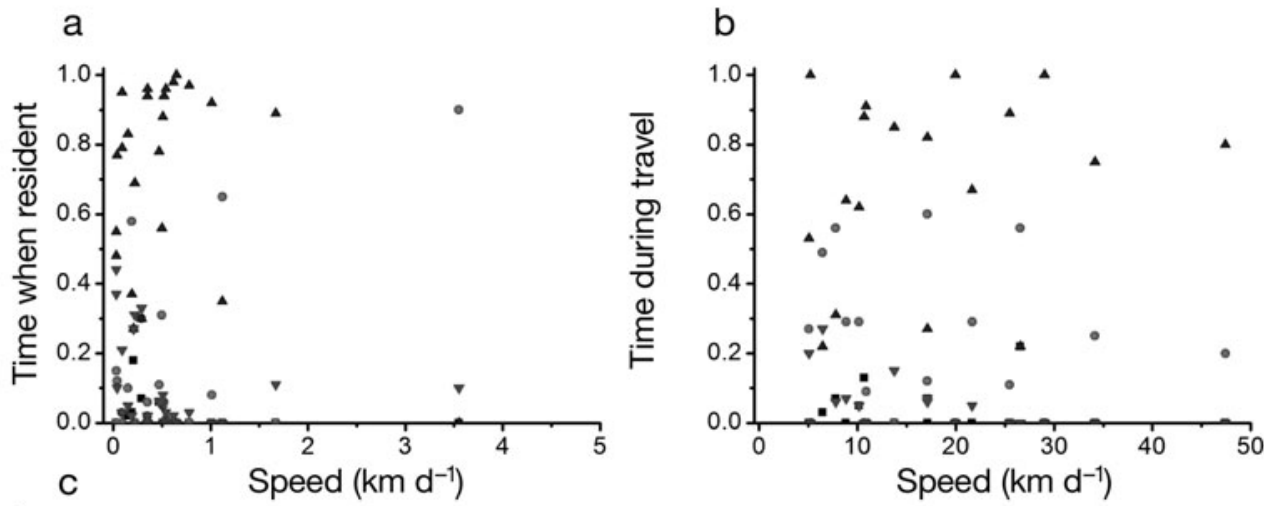

Fig. 3. Proportion of time spent by southern North Sea $\operatorname{cod}(\mathrm{n}=10)$ in each of the 4 classified behaviours: midwater (匹), continuous search $(\bullet)$, seabed with ascents $(\mathbf{\nabla})$ and seabed $(\boldsymbol{\Lambda})$, as a function of speed during periods of (a) residence and (b) directed horizontal movement. (c) Total proportion of behaviour (hatched: midwater; black: continous search; grey: seabed with ascents; white: seabed) attributed to fish during periods of residence. Note the different $x$-axis scales in (a) and (b)

The navigational cues used during these movements remain equivocal. Certainly many taxa have common navigational abilities, for example an ability to use sunbased compasses or perceived components of the earth's magnetic field (Lohmann et al. 2008). Robichaud $\&$ Rose (2001) also suggested that navigation over short ranges by cod might be attributed the attraction of grunting conspecifics on spawning grounds. They also suggest other cognitive mechanisms for cod orientation, including memory of landscape features such a bathymetry, rocky outcrops or shipwrecks. This may be a trait that continues into adulthood, and cod use features such as wrecks or oil rigs as oases during their migrations.

There were no clear distinctions between the vertical behaviours when a cod is in residence or when undertaking directed horizontal movement. Our a priori expectation was that when there is little vertical movement, cod might always be expected to be sedentary. This certainly is the case in some cases, and indeed we used this phenomenon to estimate the accuracy of our geolocation estimates. However, at other times cod showed extended horizontal travel even when there was little vertical movement. Similarly, resident cod sometimes showed quite extensive vertical movements. Given that natural predators for large cod are fairly rare, it is perhaps most likely that these vertical movements reflect prey searching behaviour. High levels of vertical activity have also been shown in other fish such as tuna (Kitagawa et al. 2007, Sippel et al. 2007) and
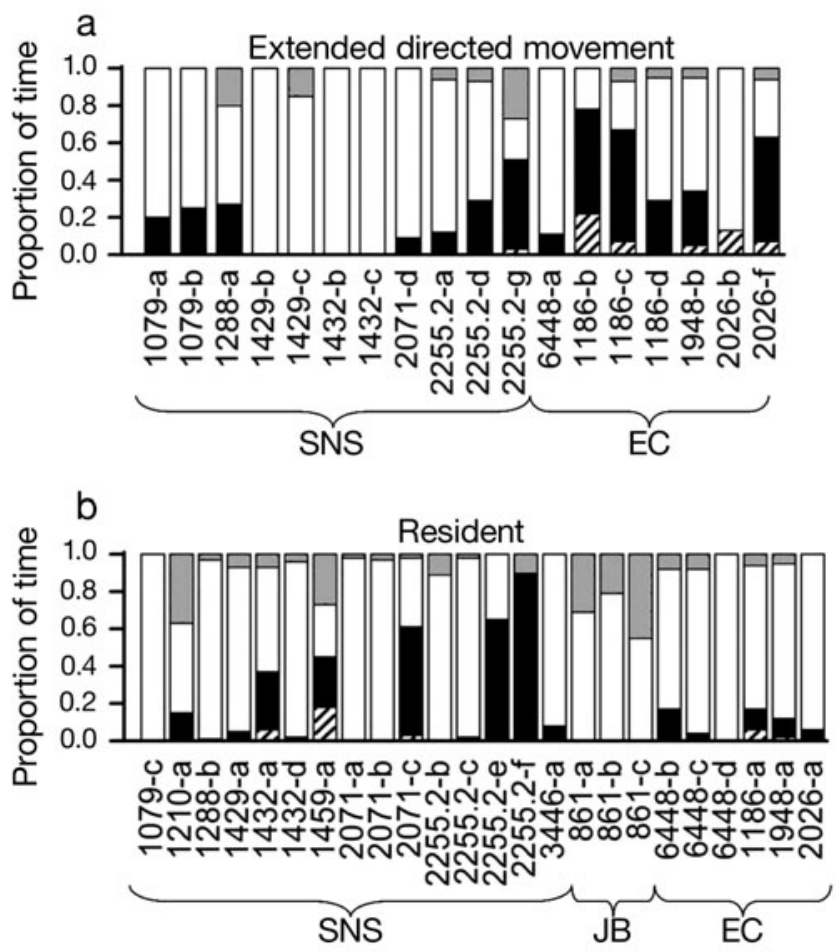

Fig. 4. Proportion of time spent by southern North Sea cod $(\mathrm{n}=14)$ in each of the 4 classified behaviours: midwater (hatched), continuous search (black), seabed with ascents (grey) and seabed (white), during periods of (a) travel and (b) residence. Location of cod tagging: Southern North Sea (SNS), Jutland Bank (JB) and English Channel (EC). Some cod are represented by $>1$ bar, in which case, each letter signifies a defined period of movement or residence 


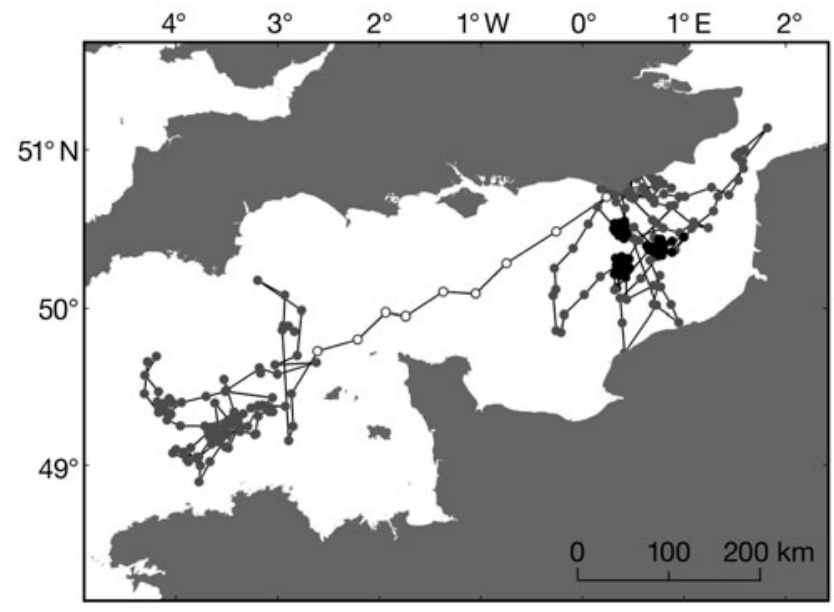

Fig. 5. Example of track for Cod 6448: released in the eastern English Channel then travelled west, showing periods of residence $(\bullet)$, extended directed movement $(\mathrm{O})$ and extended localised movement $(\bullet)$

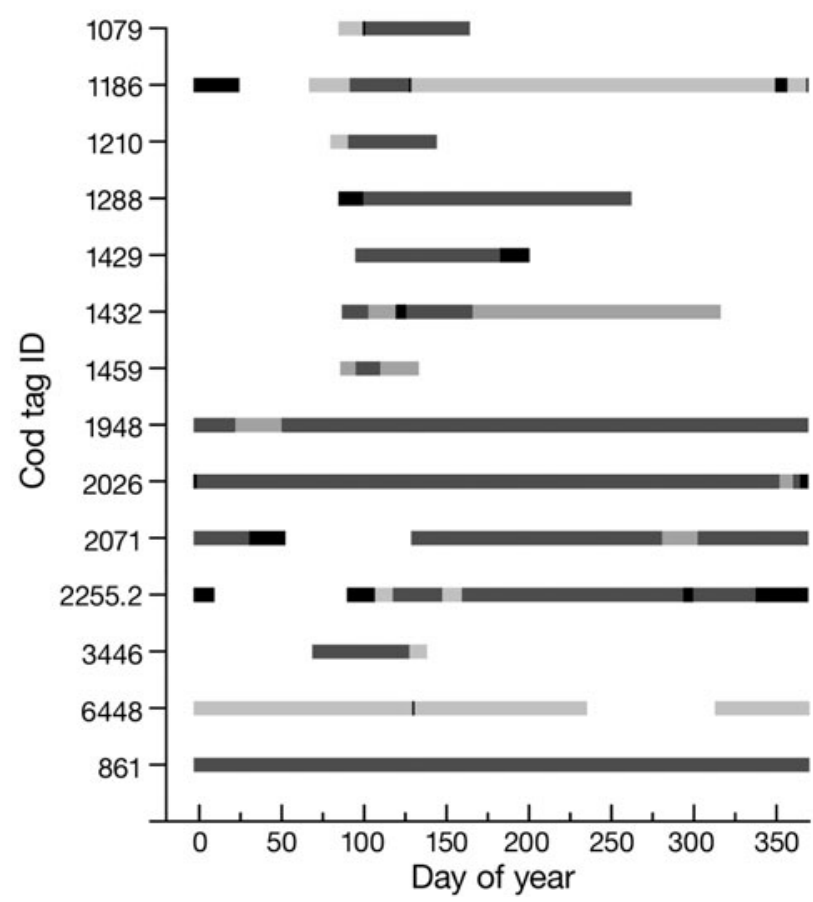

Fig. 6. Timing of migrations for individual fish. Periods of time designated as migration ( $\square$ ), residential behaviour ( $\square$ ), or 'other' if the behaviour did not fall into the category of residence or migratory for $>7 \mathrm{~d}(\square)$

sharks (Holland et al. 1999, Heithaus et al. 2002) where the water column is continually traversed to search for food or perhaps olfactory clues.

When cod were migrating, they exhibited speeds between 5 and $50 \mathrm{~km} \mathrm{~d}^{-1}$, concordant with laboratory studies in which sustained swimming speeds between 6 and $60 \mathrm{~km} \mathrm{~d}^{-1}$ (based on tests of a few hours' duration) have been reported for cod (Bainbridge 1958, Videler
1981, He \& Wardle 1986, Videler \& Wardle 1991). There are relatively few values for free-living fish, due to previous problems with following fish for long periods (Arnold et al. 1994, Nelson et al. 1997, Nakano et al. 2003), so the present results demonstrate that values at the upper end of this range are possible for free-living fish travelling 100s of $\mathrm{km}$ and clearly point to cod being accomplished long-distance travellers. Nonetheless, the average speed of travel during EDM of most cod was somewhat surprising given that cod have very little red swimming muscle and appear more adapted for short bursts of swimming (Webber et al. 2001).

When the fish were migrating, both seabed and midwater behaviours were seen, and 1 fish showed a combination of the 2 behaviours as it travelled up the east coast of England using STST. STST occurs when an animal remains near the seabed during current flow that is not in the direction the animal wishes to move in. Then when the current begins to flow in the opposite direction, the fish moves away from the seabed and travels with the current. STST is more commonly seen in flatfish such as plaice Pleuronectes platessa and is used as an efficient method to travel great distances (Hunter et al. 2004c). STST in cod has previously been shown to occur in the North Sea (Arnold et al. 1994, Righton et al. 2007), but the present results suggest that clear examples of this behaviour are relatively rare ( $7 \%$ of the time during EDM behaviour). This may be because cod do not exhibit such overt refuging or midwater behaviour during STST as plaice do, or because our sample size was not large enough to fully characterise the extent of STST in cod. Alternatively, it could be that optimum speed of travel might not be the only priority for migrating cod and that they also forage during migration, and that cod are able to travel quite rapidly without exhibiting this behaviour. In support of this, the present results showed that some cod conducted extended travel even when in prolonged association with the seabed (i.e. a tidal sine wave was frequently visible in the depth data), suggesting the fish were travelling very close to the seabed. The energetic implications of either midwater or seabed travel are not clear. Cod were very rarely close to the sea surface, so would not be subject to the problems of surface drag that many air-breathing marine species seek to avoid by swimming below the sea surface (Hertel 1966, Hays et al. 2001a). Given that cod sometimes associate with the seabed during extended horizontal movement but sometimes travel in mid-water, it might simply be that local bathymetry dictates their swimming strategy. Presumably midwater travel might be preferred when the seabed depth constantly changes, while a more consistent maximum depth would be more conducive to travelling close to the seabed. This latter strategy may also 
have the advantage of higher prey-encounter rates because many of the molluscs, crustaceans and small fish that cod feed on are also found close to the seabed (Adlerstein \& Welleman 2000).

Also evident for some cod was the repositioning of residential behaviour. Presumably this occurs when the quality of one area (e.g. prey availability) declines below some marginal value, although we have no information on patch quality, where a cod may deplete one feeding site, then search the local area, and become residential only a few $\mathrm{km}$ from its previous residence. Further quantitative studies are required to disentangle the linkages between cod behaviour and environment use.

Extended travel tended to start in the winter (December to February). Presumably these movements were predominantly associated with travel to and from spawning grounds. However, it is somewhat surprising that there was not a more marked seasonality, given that the timing of cod spawning is thought to occur mainly over a few months in early spring (Cushing \& Dickson 1976). One possibility is that the movements we recorded might not only be associated with migration to spawning grounds before the spawning season in January and February but might also reflect repositioning onto new feeding grounds once spawning is over (Turner et al. 2002, Wright et al. 2006, Righton et al. 2007, Svedäng et al. 2007). Similar spatial dynamics are shown in plaice (Hunter et al. 2004a), and are typical of migratory fish species that aggregate on spatially restricted spawning grounds before dispersal to widespread feeding grounds (e.g. bluefin tuna: Block et al. 2005). However, it is noteworthy that some cod followed for $>1$ yr never showed any extended horizontal movement. This was particular evident for one of the cod tagged in the Jutland area (Cod 861) and one in the English Channel (Cod 1948). This result suggests that either some cod are resident and therefore spawn and forage in the same locality (as in Neat et al. 2006) or they may skip breeding in some years (e.g. Rose 2003). Certainly in other taxa, non-annual breeding occurs and is associated with extended periods of time necessary to attain a sufficient body condition to initiate breeding (Hays 2000). There have been previous suggestions that cod sub-stocks in different parts of the North Sea have different dispersal patterns and hence travel different distances to spawning sites (Metcalfe 2006) and have different life-history characteristics (Wright et al. 2006). The present results support the contention that there is not a single paradigm of extended travel between spawning and foraging areas for this species, but that movements vary from individual to individual, and sub-stock to sub-stock, consistent with the concept that Atlantic cod behaviour is the result of complex interactions between biological and ecological factors (Righton et al. 2001).
Understanding the movement of cod has important implications for future management of stocks and recognising the implications of climate change. Habitatbased stock assessment models (Kupschus 2003) have been developed for the integration of behavioural and environmental data, in order to standardise catch and effort, based on estimating fishing depths of various gears in relation to the vertical distribution of the target species by time of day (Aglen et al. 1999). For conservation managers, a knowledge of when fish may be in closed areas will aid management decisions (Moustakas et al. 2006, Horwood et al. 2007). We suggest that the kind of data provided in the present study is suitable for integration into stock assessment models for exploring vulnerability to detection and catchability by all fishing gears. Our results clearly show the utility of data-storage tags for recording both the horizontal and vertical movements of cod over extended periods, and reveal the complexity of horizontal movements as well as the range of vertical movement behaviours exhibited during periods of both horizontal travel and localised residence.

Acknowledgements. We extend our gratitude to the many colleagues who contributed to this study and the many skippers and the fishermen who have cooperated with us by helping us to tag cod and also by returning tags. The study was funded by EU project CODYSSEY (Q5RT-2002-00813) and Defra (MF0154), and V.J.H. is supported by a NERC CASE studentship in collaboration with the Centre for Environment, Fisheries and Aquaculture Science, Lowestoft.

\section{LITERATURE CITED}

Adlerstein SA, Welleman HC (2000) Diel variation of stomach contents of North Sea cod (Gadus morhua) during a 24-h fishing survey: an analysis using generalized additive models. Can J Fish Aquat Sci 57:2363-2367

Aglen A, Engås A, Huse I, Michalsen K, Stensholt BK (1999) How vertical fish distribution may affect survey results. ICES J Mar Sci 56:345-360

Arnold GP, Greer Walker M, Emerson LS, Holford BH (1994) Movements of cod (Gadus morhua) in relation to the tidal streams in the southern North Sea. ICES J Mar Sci 51: 207-232

Bainbridge R (1958) The speed of swimming of fish as related to size and to the frequency and amplitude of the tail beat. J Exp Biol 35:109-133

Block BA, Teo SLH, Walli A, Boustany A and others (2005) Electronic tagging and population structure of Atlantic bluefin tuna. Nature 434:1121-1127

Bonfil R, Meyer M, Scholl MC, Johnson R and others (2005) Transoceanic migration, spatial dynamics, and population linkages of white sharks. Science 310:100-103

Bradshaw CJA, Sims DW, Hays GC (2007) Measurement error causes scale-dependent threshold erosion of biological signals in animal movement data. Ecol Appl 17:628-638

Christensen V, Guénette S, Heymans JJ, Walters CJ, Watson R, Zeller D, Pauly D (2003) Hundred-year decline of North Atlantic predatory fishes. Fish Fish 4:1-24 
Cushing DH, Dickson RR (1976) The biological response in the sea to climatic changes. Adv Mar Biol 14:1-122

Gröger JP, Rountree RA, Thygesen UH, Jones D, Martins D, $\mathrm{Xu}$ Q, Rothschild BJ (2007) Geolocation of Atlantic cod (Gadus morhua) movements in the Gulf of Maine using tidal information. Fish Oceanogr 16:317-335

Harden Jones FR, Arnold GP, Greer Walker M, Scholes P (1979) Selective tidal stream transport and the migration of plaice (Pleuronectes platessa) in the southern North Sea. J Cons Int Explor Mer 38:331-337

- Hays GC (2000) The implications of variable remigration intervals for the assessment of population size in marine turtles. J Theor Biol 206:221-227

Hays GC, Webb PI, Hayes JP, Priede IG, French J (1991) Satellite tracking of a loggerhead turtle (Caretta caretta) in the Mediterranean. J Mar Biol Assoc UK 71:743-746

Hays GC, Akesson S, Broderick AC, Glen F and others (2001a) The diving behaviour of green turtles undertaking oceanic migration to and from Ascension island: dive durations, dive profiles and depth distributions. J Exp Biol 204:4093-4098

Hays GC, Akesson S, Godley BJ, Luschi P, Santidrian P (2001b) The implications of location accuracy for the interpretation of satellite-tracking data. Anim Behav 61: 1035-1040

Hays GC, Hobson VJ, Metcalfe JD, Righton D, Sims DW (2006) Flexible foraging movements of leatherback turtles across the north Atlantic Ocean. Ecology 87:2647-2656

He P, Wardle CS (1986) Tilting behaviour of the Atlantic mackerel, Scomber scombrus, at low swimming speeds. J Fish Biol 29(Suppl A):223-232

> Heithaus MR, Dill LM, Marshall GJ, Buhleier B (2002) Habitat use and foraging behavior of tiger sharks Galeocerdo cuvier in a seagrass ecosystem. Mar Biol 140:237-248

Hertel H (1966) Structure, form, movement. Reinhold, New York

- Hobson VJ, Righton D, Metcalfe JD, Hays GC (2007) Vertical movements of cod in the North Sea. Mar Ecol Prog Ser 347:101-110

Holland KN, Wetherbee BM, Lowe CG, Meyer CG (1999) Movements of tiger sharks (Galeocerdo cuvier) in coastal Hawaiian waters. Mar Biol 134:665-673

Horwood J, O'Brien C, Darby C (2006) North Sea cod recovery? ICES J Mar Sci 63:961-968

Horwood JW, Nichols JH, Milligan S (2007) Evaluation of closed areas for fish stock conservation. J Appl Ecol 35: 893-903

Hunter E, Aldridge JN, Metcalfe JD, Arnold GP (2003) Geolocation of free-ranging fish on the European continental shelf as determined from environmental variables. I. Tidal location method. Mar Biol 142:601-609 doi:10.1007/ s00227-002-0984-5

- Hunter E, Metcalfe JD, Arnold GP, Reynolds JD (2004a) Impacts of migratory behaviour on population structure in North Sea plaice. J Anim Ecol 73:377-385

> Hunter E, Metcalfe JD, Holford BH, Arnold GP (2004b) Geolocation of free-ranging fish on the European continental shelf as determined from environmental variables. II. Reconstruction of plaice ground tracks. Mar Biol 144: $787-798$

Hunter E, Metcalfe JD, O'Brien CM, Arnold GP, Reynolds JD (2004c) Vertical activity patterns of free-swimming adult plaice in the southern North Sea. Mar Ecol Prog Ser 279: 261-273

Hunter E, Berry F, Buckley AA, Stewart C, Metcalfe JD (2006) Seasonal migration of thornback rays and implications for closure management. J Appl Ecol 43:710-720
Kitagawa T, Boustany AM, Farwell CJ, Williams TD, Castleton MR, Block BA (2007) Horizontal and vertical movements of juvenile bluefin tuna (Thunnus orientalis) in relation to seasons and oceanographic conditions in the eastern Pacific Ocean. Fish Oceanogr 16:409-421

> Kupschus S (2003) Development and evaluation of statistical habitat suitability models: an example based on juvenile spotted seatrout Cynoscion nebulosus. Mar Ecol Prog Ser 265:197-212

Lohmann KJ, Luschi P, Hays GC (2008) Goal navigation and island-finding in sea turtles. J Exp Mar Biol Ecol 356: 83-95

> Metcalfe JD (2006) Fish population structuring in the North Sea: understanding processes and mechanisms from studies of the movements of adults. J Fish Biol 69(Suppl C): $48-65$

Metcalfe JD, Arnold GP (1997) Tracking fish with electronic tags. Nature 387:665-666

Moustakas A, Silvert W, Dimitromanolakis A (2006) A spatially explicit learning model of migratory fish and fishers for evaluating closed areas. Ecol Model 192:245-258

Myers RA, Hutchings JA, Barrowman NJ (1997) Why do fish stocks collapse? The example of cod in eastern Canada. Ecol Appl 7:91-106

Nakano H, Matsunaga H, Okamoto H, Okazaki M (2003) Acoustic tracking of bigeye thresher shark Alopias superciliosus in the eastern Pacific Ocean. Mar Ecol Prog Ser 265:255-261

> Neat F, Wright P, Zuur A, Gibb I and others (2006) Residency and depth movements of a coastal group of Atlantic cod (Gadus morhua). Mar Biol 148:643-654

> Nelson DR, McKibben JN, Strong WR, Lowe CG, Sisneros JA, Schroeder DM, Lavenberg RJ (1997) An acoustic tracking of a megamouth shark, Megachasma pelagios: a crepuscular vertical migrator. Environ Biol Fishes 49:389-399

> Neuenfeldt S, Hinrichsen $\mathrm{HH}$, Nielsen A, Andersen $\mathrm{KH}$ (2007) Reconstructing migrations of individual cod (Gadus morhua L.) in the Baltic Sea by using electronic data storage tags. Fish Oceanogr 16:526-535

Nichol DG, Chilton EA (2006) Recuperation and behaviour of Pacific cod after barotrauma. ICES J Mar Sci 63:83-94

O'Brien CM, Fox CJ, Planque B, Casey J (2000) Fisheries: climate variability and North Sea cod. Nature 404:142

Patterson TA, Thomas L, Wilcox C, Ovaskainen O, Matthiopoulos J (2008) State-space models of individual animal movement. Trends Ecol Evol 23:87-94

> Pedersen MW, Righton D, Thygesen UH, Andersen KH, Madsen H (2008) Geolocation of North Sea cod using hidden Markov models and behavioural switching. Can J Fish Aquat Sci 65:2367-2377

Pinaud D, Weimerskirch H (2007) At-sea distribution and scale-dependent foraging behaviour of petrels and albatrosses: a comparative study. J Anim Ecol 76:9-19

Righton D, Mills C (2008) Reconstructing the movements of free-ranging demersal fish in the North Sea: a datamatching and simulation method. Mar Biol 153:507-521

Righton D, Metcalfe JD, Connolly P (2001) Different behaviour of North and Irish Sea cod. Nature 411:156

$>$ Righton D, Kjesbu OS, Metcalfe JD (2006) A field and experimental evaluation of the effect of data storage tags on the growth of cod. J Fish Biol 68:385-400

Righton D, Quayle VA, Hetherington S, Burt G (2007) Movements and distribution of cod (Gadus morhua) in the southern North Sea and English Channel: results from conventional and electronic tagging experiments. J Mar Biol Assoc UK 87:599-613

Roberts CM, Hawkins JP, Gell FR (2005) The role of marine 
reserves in achieving sustainable fisheries. Philos Trans R Soc Lond B 360:123-132

Robichaud D, Rose GA (2001) Multiyear homing of Atlantic cod to a spawning ground. Can J Fish Aquat Sci 58: 2325-2329

Robichaud D, Rose GA (2004) Migratory behaviour and range in Atlantic cod: inference from a century of tagging. Fish Fish 5:185-214

Rose GA (2003) Monitoring coastal northern cod: towards an optimal survey of Smith Sound, Newfoundland. ICES J Mar Sci 60:453-462

Schaefer KM, Fuller DW (2006) Comparative perfomance of current-generation geolocating archival tags. Mar Technol Soc J 40:15-28

Schofield G, Bishop CM, Katselidis KA, Dimopoulos P, Pantis JD, Hays GC (2009) Microhabitat selection by sea turtles in a dynamic thermal marine environment. J Anim Ecol 78:14-21

Sims DW, Southall EJ, Tarling GA, Metcalfe JD (2005) Habitat-specific normal and reverse diel vertical migration in the plankton-feeding basking shark. J Anim Ecol 74: 755-761

Sippel TJ, Davie PS, Holdsworth JC, Block BA (2007) Striped marlin (Tetrapturus audax) movements and habitat utilization during a summer and autumn in the Southwest Pacific Ocean. Fish Oceanogr 16:459-472

Stewart BS, Leatherwood S, Yochem PK, Heide-Jorgensen MP (1989) Harbour seal tracking and telemetry by satellite. Mar Mamm Sci 5:361-375

Svedäng H, Righton D, Jonsson P (2007) Migratory behaviour

Editorial responsibility: Hans Heinrich Janssen, Oldendorf/Luhe, Germany of Atlantic cod Gadus morhua: natal homing is the prime stock-separating mechanism. Mar Ecol Prog Ser 345:1-12

Teo SLH, Boustany A, Blackwell S, Walli A, Weng KC, Block BA (2004) Validation of geolocation estimates based on light level and sea surface temperature from electronic tags. Mar Ecol Prog Ser 283:81-98

- Turner K, Righton D, Metcalfe JD (2002) The dispersal patterns and behaviour of North Sea cod (Gadus morhua) studied using electronic data storage tags. Hydrobiologia 483:201-208

Videler JJ (1981) Swimming movements, body structure and propulsion in cod (Gadus morhua). In: Day MH (ed) Vertebrate locomotion. Academic Press, London, p 1-27

> Videler JJ, Wardle CS (1991) Fish swimming stride by stride: speed limits and endurance. Rev Fish Biol Fish 1:23-40

> Vincent C, McConnell BJ, Ridoux V, Fedak MA (2002) Assessment of Argos location accuracy from satellite tags deployed on captive gray seals. Mar Mamm Sci 18:156-166

Walsh SJ, Godø OR, Michalsen K (2004) Fish behaviour relevant to fish catchability. ICES J Mar Sci 61:1238-1239

- Webber DM, Boutilier RG, Kerr SR, Smale MJ (2001) Caudal differential pressure as a predictor of swimming speed of cod (Gadus morhua). J Exp Biol 204:3561-3570

Weimerskirch $H$, Salamolard M, Sarrazin F, Jouventin P (1993) Foraging strategy of wandering albatrosses through the breeding season: a study using satellite telemetry. Auk 110:325-342

Wright PJ, Galley E, Gibb IM, Neat FC (2006) Fidelity of adult cod to spawning grounds in Scottish waters. Fish Res 77 : $148-158$

Submitted: April 4, 2008; Accepted: January 26,2009

Proofs received from author(s): March 10, 2009 